\title{
Validation of the prognostic relevance of plasma C-reactive protein levels in soft-tissue sarcoma patients
}

\author{
J Szkandera ${ }^{1}$, A Gerger ${ }^{1,2}$, B Liegl-Atzwanger ${ }^{3}$, G Absenger ${ }^{1}$, M Stotz ${ }^{1}$, H Samonigg ${ }^{1}$, W Maurer-Ertl ${ }^{4}$, \\ T Stojakovic $^{5}$, F Ploner ${ }^{1}$, A Leithner ${ }^{4}$ and M Pichler ${ }^{\star, 1}$ \\ ${ }^{1}$ Division of Clinical Oncology, Department of Medicine, Medical University of Graz, Graz, Austria; ${ }^{2}$ Research Unit Genetic \\ Epidemiology and Pharmacogenetics, Division of Clinical Oncology, Department of Medicine, Medical University of Graz, Graz, \\ Austria; ${ }^{3}$ Institute of Pathology, Medical University of Graz, Graz, Austria; ${ }^{4}$ Department of Orthopaedic Surgery, Medical University \\ of Graz, Graz, Austria and ${ }^{5}$ Clinical Institute of Medical and Chemical Laboratory Diagnostics, Medical University of Graz, \\ Graz, Austria
}

Background: The concept of the involvement of systemic inflammation in cancer progression and metastases has gained attraction within the past decade. C-reactive protein (CRP), a non-specific blood-based marker of the systemic inflammatory response, has been associated with decreased survival in several cancer types. The aim of the present study was to validate the prognostic value of pre-operative plasma CRP levels on clinical outcome in a large cohort of soft-tissue sarcoma (STS) patients.

Methods: Three hundred and four STS patients, operated between 1998 and 2010, were retrospectively evaluated. CRP levels and the impact on cancer-specific survival (CSS), disease-free survival (DFS) and overall survival (OS) were assessed using Kaplan-Meier curves and univariate as well as multivariate Cox proportional models. Additionally, we developed a nomogram by supplementing the plasma CRP level to the well-established Kattan nomogram and evaluated the improvement of predictive accuracy of this novel nomogram by applying calibration and Harrell's concordance index (c-index).

Results: An elevated plasma CRP level was significantly associated with established prognostic factors, including age, tumour grade, size and depth $(P<0.05)$. In multivariate analysis, increased CRP levels were significantly associated with a poor outcome for CSS $(H R=2.05 ; 95 \% \mathrm{Cl}=1.13-3.74 ; P=0.019)$ and DFS $(H R=1.88 ; 95 \% \mathrm{Cl}=1.07-3.34 ; P=0.029)$. The estimated c-index was 0.74 using the original Kattan nomogram and 0.77 when the plasma CRP level was added.

Conclusion: An elevated pre-operative CRP level represents an independent prognostic factor that predicts poor prognosis and improves the predictive ability of the Kattan nomogram in STS patients. Our data suggest to further prospectively validate its potential utility for individual risk stratification and clinical management of STS patients.

Soft-tissue sarcomas (STSs) are a heterogeneous group of rare tumours that arise predominantly from the embryonic mesoderm (Cormier and Pollock, 2004). A number of large-scale studies have defined several relevant prognostic factors associated with survival, including tumour size, tumour depth, site and grade (Stefanovski et al, 2002; Stojadinovic et al, 2002). Furthermore, Kattan et al (2002) developed a postoperative prognostic model that predicts sarcoma-specific death, based on traditional prognostic factors such as age at diagnosis, tumour size, histological grade, histological subtype, tumour depth and site. This nomogram is useful for general risk assessment and has the potential value in determining surgical strategy and adjuvant management (Kattan et al, 2002). However, the overall 5-year survival rate accounts for only $50 \%$, and particularly, STS patients with high-grade tumours 
are at significant risk of relapse (Cormier and Pollock, 2004). Robust and reliable prognostic factors might be helpful to allow treatment options and follow-up schemes to be tailored to the individual risk situation. Hence, there is an urgent need for an easily determinable, widely applicable and cheap marker, which might help to improve the predictive ability for identification of patients with a high risk for tumour recurrence and sarcomarelated death. Growing evidence has expanded that systemic inflammation has a role in cancer progression (Balkwill and Mantovani, 2001; Coussens and Werb, 2002). Cancer cells interact directly and indirectly with host inflammatory cells. This tumourassociated inflammatory response may lead to an alteration in cancer cell biology and activation of stromal cells in the tumour microenvironment by upregulation of cytokines and inflammatory mediators, inhibition of apoptosis, induction of angiogenesis, stimulation of DNA damage and immunosuppression and remodelling of the extracellular matrix, hence promoting tumour growth and metastasis (Balkwill and Mantovani, 2001; Coussens and Werb, 2002). C-reactive protein (CRP) is a non-specific bloodbased marker of acute-phase inflammatory response. Increased blood levels of CRP could be detected in many cancer types, including colorectal and lung cancer (Hara et al, 2007; Groblewska et al, 2008). Furthermore, elevated concentrations of CRP before treatment had been previously shown to serve as an independent prognostic marker for decreased survival in oesophageal cancer, hepatocellular cancer, colorectal cancer, renal cell cancer, ovarian cancer and non-small cell lung cancer (Hashimoto et al, 2005; Gockel et al, 2006; Lamb et al, 2006; Crozier et al, 2007; Hefler et al, 2008; Gagnon et al, 2010). However, there is only little evidence available in the literature regarding the prognostic value of CRP levels in patients with STS (Nakanishi et al, 2002; Nakamura et al, 2012, 2013). Two previous studies included rather small number of patients and used different cutoff values to define elevated CRP levels (Nakanishi et al, 2002; Nakamura et al, 2012). Therefore, in the present study, we validated the prognostic significance of pre-operative plasma CRP levels on cancer-specific survival (CSS), metastasis-free survival (MFS) and overall survival (OS) in a large cohort of $>300$ STS patients. After validation, we finally examined the potential utility to improve the predictive ability of the well-established Kattan prognostic nomogram by including the plasma CRP levels to this risk assessment tool (Kattan et al, 2002).

\section{MATERIALS AND METHODS}

Subjects. Three hundred and four patients with consecutively diagnosed and histologically confirmed STS, who had been operated between March 1998 and November 2010 at the Department of Orthopaedic Surgery, Medical University of Graz, Graz, Austria, were included in this retrospective study. Follow-up was performed until January 2012. All patients were included in the follow-up programme of the Department of Orthopaedic Surgery and the Division of Clinical Oncology, Department of Medicine, Medical University of Graz, Graz, Austria, providing follow-up examinations at regular intervals (3-month intervals in years 1-3, 6-month intervals in years $4-5$ and 12-month intervals in years 6-15 after diagnosis). The laboratory data, including preoperative plasma CRP levels, were obtained by pre-operative exploration 1-7 days before surgery. Follow-up investigations included clinical check-up and radiological analyses (computed tomography, magnetic resonance imaging, abdominal ultrasound and chest X-ray). Clinical data including treatment scheme (surgery, radiotherapy and chemotherapy) and histopathological diagnosis including tumour grade were retrospectively obtained from the patients' history. For the present study, all histological specimens were centrally reviewed by an experienced pathologist (BL-A). All sarcomas were diagnosed according to the current WHO classification soft tissue and bone tumours (Fletcher et al, 2013). Tumours were graded according to the French Federation of Cancer Centres Sarcoma Group (FNCLCC) grading system (Coindre, 2006) or tumour grade was defined by tumour entity. Clinical staging was determined based on the recommendations of the American Joint Committee on Cancer (Edge et al, 2010). Malignant fibrous histiocytomas were re-classified according to the current diagnostic criteria (Liegl-Atzwanger et al, 2009; Fletcher et al, 2013). This study has been approved by the Institutional Review Board of the Medical University of Graz (25187 ex 12/13).

Statistical analysis. The primary end point of this study was CSS, which was calculated from the date of diagnosis to the date of cancer-related death. Secondary end points included OS (time between diagnosis and death by any cause) and DFS (time between diagnosis and occurrence of local recurrence or distant metastases). The continuous variable CRP was analysed as a dichotomous variable. To determine an optimal cutoff value, we performed a receiver operating curve analysis as previously described (Absenger et al, 2013). The association between the plasma CRP level and clinico-pathological parameters was evaluated by non-parametric tests (Mann-Whitney $U$ and chi square test). Patients' clinical end points were calculated using the Kaplan-Meier method and compared by the log-rank test. Backward stepwise multivariate Cox proportion analysis was performed to determine the influence of age, gender, tumour size, grade and depth and plasma CRP levels on CSS, MFS and OS. Hazard ratios (HRs) estimated from the Cox analysis were reported as relative risks with corresponding 95\% confidence intervals (CIs). Nomogram validation comprised two steps: First, to address the calibration accuracy of the nomogram, we plotted the survival probabilities predicted by the nomogram against the corresponding observed survival probabilities obtained by the Kaplan-Meier method and then comparing group means with the observed Kaplan-Meier estimates of sarcoma (cancer)-specific 12-year survival as described in the original study by Kattan et al (Kattan et al, 2002). Second, the extent of discrimination was quantified using the Harrel's concordance index (c-index) (Pichler et al, 2013). The interpretation of the c-index is similar to the interpretation of the area under an ROC curve. A value of 1.0 indicates that the features of the model perfectly separate patients with different outcomes while a value of 0.5 indicates the features that contain prognostic information equal to that obtained by chance alone. The nomogram is based on the Cox model and predicts the probability that the patient will die of sarcoma within 12 years of his initial surgery. All statistical analyses were performed using the Statistical Package for Social Sciences version 20.0 (SPSS Inc., Chicago, IL, USA) or R programme. A two-sided $P<0.05$ was considered statistically significant.

\section{RESULTS}

Overall, there were 158 male and 146 female patients with STS. The median age at diagnosis was 61 years (interquartile range: 47-72 years). The median follow-up period was 36 months (range, $0-162$ months). The mean tumour size at diagnosis was $9.5 \pm 6.7 \mathrm{~cm}$ (range, $1-47 \mathrm{~cm}$ ). One hundred and ninety-two patients had grade 3 sarcomas according to the FNCLCC grading system, 57 patients were histologically classified as having grade 1 and 55 patients had grade 2 tumours. The 304 patients were histologically classified as follows: 91 myxofibrosarcomas, 75 liposarcomas, 37 leiomyosarcomas, 26 synovial sarcomas, 13 malignant peripheral nerve sheath tumours, and 62 other histological subtypes. The primary tumour 
sites were localised at the upper extremities $(n=77)$, lower extremities $(n=192)$, thorax/trunk $(n=28)$, retroperitoneal/ intraabdominal $(n=4)$ and head/neck $(n=3)$. The tumour depth was defined superficial in 83 patients and deep in 221 patients, respectively. Based on the AJCC staging system, 13 patients were classified as IA, 42 patients as IB, 88 patients as IIA, 32 patients as IIB, 117 patients as III and 12 patients as IV. All STS patients underwent surgery, and $193(63.5 \%)$ patients received adjuvant radiation therapy for the primary tumour site. Thirty-nine $(12.8 \%)$ of the 304 sarcoma patients underwent adjuvant chemotherapy. The median pre-operative plasma CRP level was $3.3 \mathrm{mgl}^{-1}$ (interquartile range: $1-11.5 \mathrm{mgl}^{-1}$ ). In an attempt to test whether gradually increasing CRP levels influence the clinical outcome of STS patients, first we subdivided the patients into four groups according to their quartiles. Kaplan-Meier curve for CSS, which comprises four groups according to the CRP level, are shown in Figure 1. Pairwise log-rank tests indicate significant differences between the highest fourth quartile (CRP level $>11.5 \mathrm{mgl}^{-1}$ ) compared with the first $\left(<1 \mathrm{mgl}^{-1} ; \quad P=0.011\right)$, second (1-3.2 $\left.\mathrm{mgl}^{-1} ; P<0.001\right)$ and third $\left(3.2-11.5 \mathrm{mgl}^{-1} ; P=0.028\right)$ quartiles, respectively. Based on these findings, we determined by applying ROC analysis a cutoff value of $6.9 \mathrm{mgl}^{-1}$ as optimal to discriminate between CSS and death. Consequently, we separated patients into two groups according to low CRP levels $\left(<6.9 \mathrm{mgl}^{-1}\right)$ or high CRP levels $\left(\geqslant 6.9 \mathrm{mgl}^{-1}\right)$ and tested the association between pre-operative plasma CRP levels and other clinico-pathological factors. The median observational period was 77 months (interquartile range 71 months) in the group of low CRP levels and 81 months (interquartile range 67 months) in the group of high CRP levels. Elevated plasma CRP levels significantly correlated with older age, high tumour grade, deep tumour location and large tumour size and stage $(P<0.05)$, whereas no association with gender and tumour site could be found (Table 1).

Five-year estimated survival rate for patients with low CRP levels were $92.8 \%$ compared with $73.4 \%$ of patients with high CRP levels $(P<0.001)$. To investigate whether plasma CRP level and other clinico-pathological factors are associated with clinical outcome of STS patients, univariate and multivariate Cox proportional models for all three different end points were

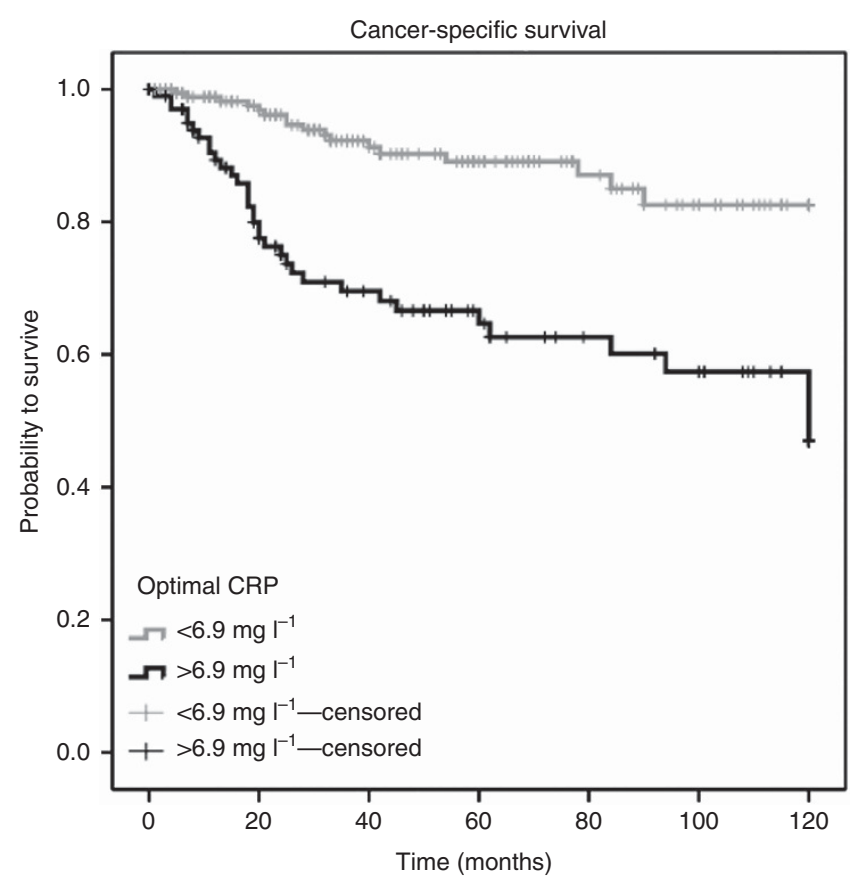

Figure 1. Kaplan-Meier curve for cancer-specific survival regarding low vs $C$-reactive protein levels $(P<0.001)$. calculated. Among the 304 STS patients, disease recurrence was diagnosed in 34 of 223 (15.2\%) patients with low and in 26 of 79 (32.9\%) patients with high CRP levels $(P<0.001)$. Cancer-related and overall deaths occurred in $26(11.7 \%)$ and 56 (25.1\%) patients with low and in $25(30.8 \%)$ and $42(51.9 \%)$ patients with high CRP levels, respectively $(P<0.001$ for both end points). Figures 2,3 and 4 show the Kaplan-Meier curves for CSS, DFS and OS and reveal that a high plasma CRP level is a consistent factor for poor prognosis in STS patients $(P<0.001$ for all three tested end points, log-rank test). Univariate analysis identified high tumour grade (G1 vs G2 vs G3, $P<0.05)$, large tumour size $(<5 \mathrm{~cm} v s \geqslant 5 \mathrm{~cm}, P<0.05)$, high AJCC stage and elevated CRP $\left(<10 \mathrm{mgl}^{-1}\right.$ vs $\geqslant 10 \mathrm{mgl}^{-1}, P<0.001$ for all three end points) as poor prognostic factors for CSS, DFS and OS in this study cohort. Additionally, high age ( $<65$ years $v s \geqslant 65$ years, $P<0.05)$ was a poor prognostic factor with regards to DFS and OS. Gender and tumour depth were not significantly associated with clinical outcome (Tables 2, 3 and 4).

Table 1. Relation between clinico-pathological parameters and pre-operative CRP levels of patients with soft-tissue sarcoma ( $n=304)$

\begin{tabular}{|l|c|c|c|}
\hline \multicolumn{5}{|l|}{$\begin{array}{c}\text { CRP level } \\
<6.9 \mathrm{mgl}^{-1}\end{array}$} & $\begin{array}{c}\text { CRP level } \\
\mathbf{6 . 9} \mathrm{mgl} \mathrm{I}^{-1}\end{array}$ & P-value \\
\hline Age at operation (years) & 125 & 57 & 0.044 \\
\hline$<65$ & 70 & 52 & \\
\hline 65 & & & \\
\hline
\end{tabular}

Gender

\begin{tabular}{|l|r|r|l|}
\hline Female & 90 & 56 & 0.382 \\
Male & 105 & 53 & \\
\hline
\end{tabular}

Tumour depth

\begin{tabular}{|l|r|r|l|}
\hline Superficial & 64 & 19 & 0.004 \\
Deep & 131 & 90 & \\
\hline
\end{tabular}

Tumour grade

\begin{tabular}{|l|r|r|l|}
\hline G1+G2 & 87 & 25 & $<0.001$ \\
G3 & 108 & 84 & \\
\hline
\end{tabular}

Tumour size

\begin{tabular}{|l|r|r|r|}
\hline$<5 \mathrm{~cm}$ & 59 & 13 & $<0.001$ \\
$\geqslant 5 \mathrm{~cm}$ & 136 & 96 & \\
\hline
\end{tabular}

Tumour site

Upper extremity

Lower extremity

Thoracic/trunk

Retroabdominal/intra-abdominal Head/neck

Tumour histology

Myxofibrosarcoma

Liposarcoma

Leiomyosarcoma

Synovial sarcoma

MPNST

Others

\begin{tabular}{r|r}
58 & 19 \\
115 & 77 \\
18 & 10 \\
3 & \\
1 &
\end{tabular}

\begin{tabular}{r|r}
19 & 0.129 \\
77 & \\
10 & \\
1 & \\
2 &
\end{tabular}

AJCC stage

$I A+I B$

$\|A+\| B$

III + IV

\begin{tabular}{r|r|r|}
\hline 58 & 33 & 0.032 \\
57 & 18 & \\
16 & 21 & \\
17 & 9 & \\
7 & 6 & \\
40 & 22 & \\
& \multicolumn{2}{|}{} \\
\multicolumn{4}{|c|}{} \\
47 & 8 & $<0.001$ \\
93 & 27 & \\
55 & 74 & \\
\hline
\end{tabular}

Abbreviations: $\mathrm{AJCC}=$ American Joint Committee on Cancer; $\mathrm{CRP}=\mathrm{C}$-reactive protein MPNST = malignant peripheral nerve sheath tumour. 


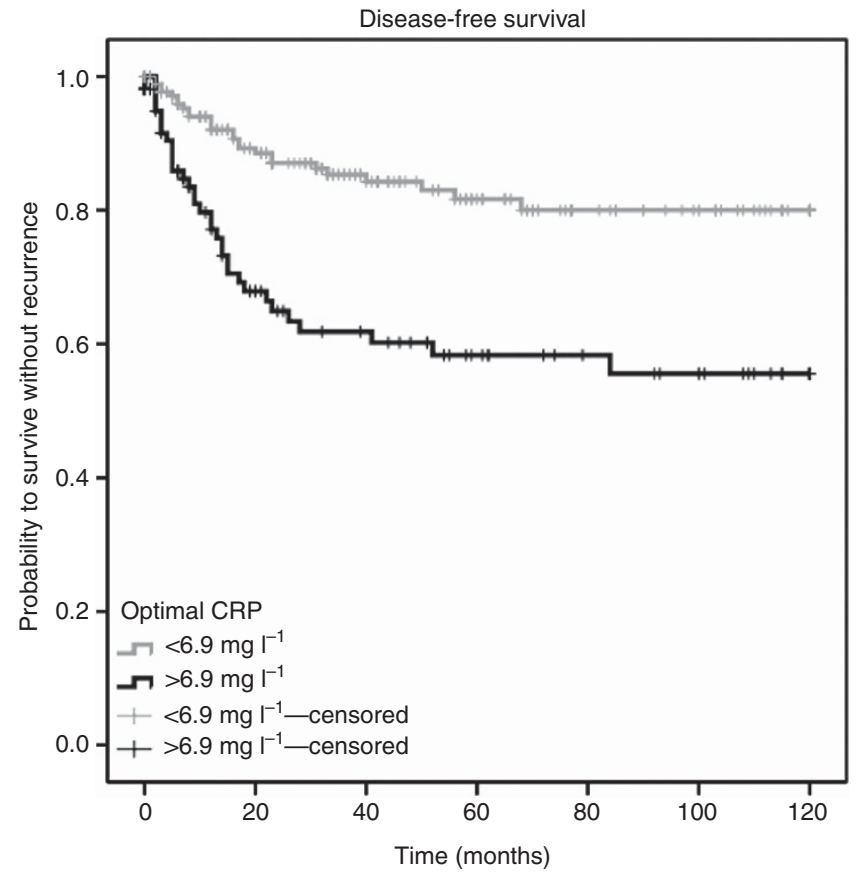

Figure 2. Kaplan-Meier curve for disease-free survival regarding low vs high C-reactive protein levels $(P<0.001)$.

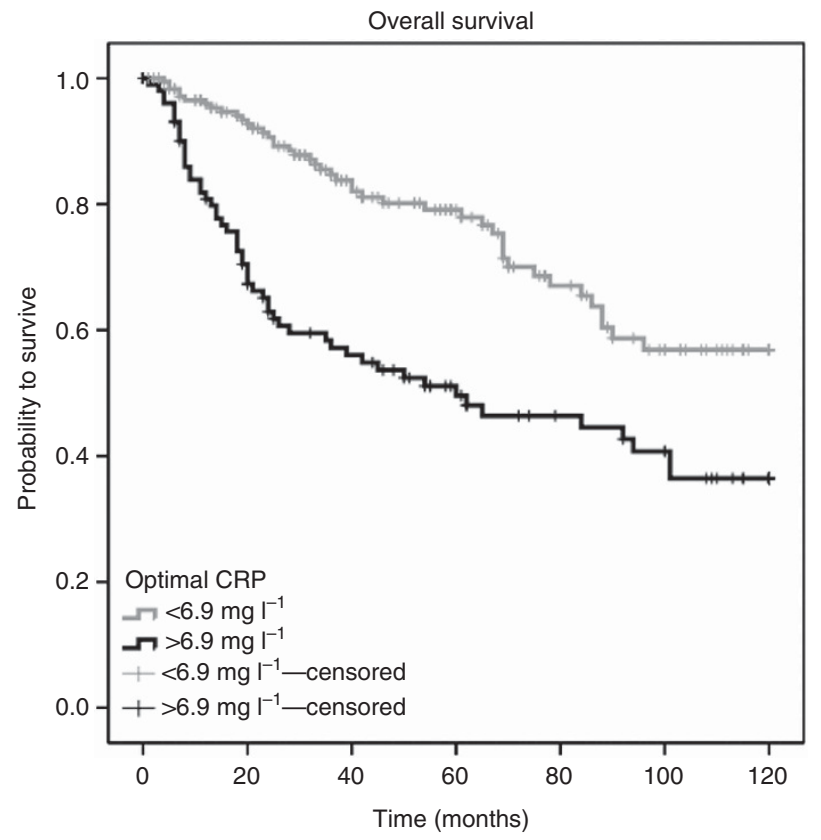

Figure 3. Kaplan-Meier curve for overall survival regarding low vs high C-reactive protein levels $(P<0.001)$.

To determine the independent prognostic value of plasma CRP for CSS, DFS and OS, a multivariate analysis using a Cox proportional hazard model was performed. In the multivariate analysis that included age, gender, tumour grade, tumour size and CRP levels, we identified tumour grade, tumour stage and CRP as independent prognostic factors for CSS (HR: 2.25; 95\% $\mathrm{CI}=1.21-4.18 ; P=0.010$; Table 2 ). With regards to DFS, tumour grade, tumour stage and CRP were identified as independent prognostic markers for clinical outcome (Table 3). With regards to OS, gender, tumour grade, tumour stage and CRP showed a significant association with survival (Table 4).

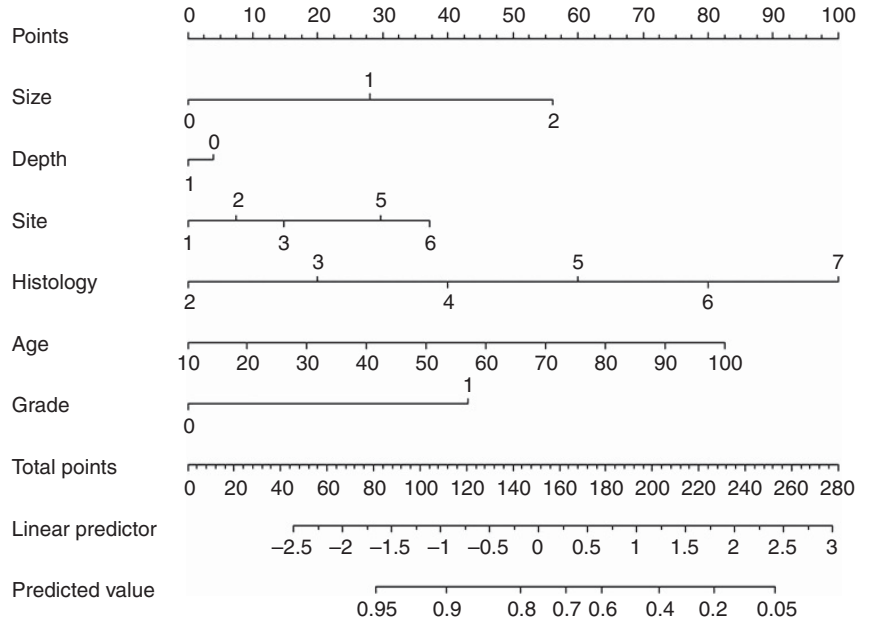

Figure 4. Original published Kattan nomogram for predicting 12-year sarcoma-specific survival. Size: $0<5 \mathrm{~cm}, 15-10 \mathrm{~cm}, 2>10 \mathrm{~cm}$; Depth: 1 = superficial, 2 =deep; Site: $1=$ upper extremities, $2=$ lower extremities, $3=$ visceral, $4=$ thoracic, $5=$ retro/intraabdominal, 6 = head/neck; histology: 1 = fibrosarcoma, 2 = liposarcoma, 3 = leiomyosarcoma, $4=$ malignant fibrous histiocytoma, $5=$ malignant peripheral nerve tumour; Grade: $1=$ low grade, $2=$ high grade (Kattan et al, 2002).

Table 2. Univariate and multivariate Cox proportional analysis regarding cancer-specific survival

\begin{tabular}{|c|c|c|c|c|}
\hline & \multicolumn{2}{|c|}{ Univariate analysis } & \multicolumn{2}{|c|}{ Multivariate analysis } \\
\hline Parameter & $\mathrm{HR}(95 \% \mathrm{Cl})$ & $P$-value & $\mathrm{HR}(95 \% \mathrm{Cl})$ & $\boldsymbol{P}$-value \\
\hline \multicolumn{5}{|c|}{ Age at operation (years) } \\
\hline $\begin{array}{l}<65 \\
\geqslant 65\end{array}$ & $\begin{array}{c}1 \text { (referent) } \\
1.37(0.79-2.37)\end{array}$ & 0.268 & $\begin{array}{c}1 \text { (referent) } \\
1.32 \text { (0.74-2.35) }\end{array}$ & 0.353 \\
\hline \multicolumn{5}{|l|}{ Gender } \\
\hline $\begin{array}{l}\text { Female } \\
\text { Male }\end{array}$ & $\begin{array}{c}1 \text { (referent) } \\
0.86(0.50-1.49)\end{array}$ & 0.589 & $\begin{array}{c}1 \text { (referent) } \\
0.70(0.39-1.25)\end{array}$ & 0.225 \\
\hline \multicolumn{5}{|c|}{ Tumour depth } \\
\hline $\begin{array}{l}\text { Superficial } \\
\text { Deep }\end{array}$ & $\begin{array}{c}1 \text { (referent) } \\
1.39(0.71-2.71)\end{array}$ & 0.335 & $\begin{array}{c}1 \text { (referent) } \\
1.03(0.51-2.08)\end{array}$ & 0.926 \\
\hline \multicolumn{5}{|c|}{ Tumour grade } \\
\hline $\begin{array}{l}\mathrm{G} 1 \\
\mathrm{G} 2 \\
\mathrm{G} 3\end{array}$ & $\begin{array}{c}1 \text { (referent) } \\
2.67(0.84-8.51) \\
4.24(1.51-11.94)\end{array}$ & $\begin{array}{l}0.098 \\
0.006\end{array}$ & $\begin{array}{c}1 \text { (referent) } \\
0.48(0.77-3.00) \\
0.21(0.05-0.98)\end{array}$ & $\begin{array}{l}0.434 \\
0.047\end{array}$ \\
\hline \multicolumn{5}{|l|}{ Tumour size } \\
\hline $\begin{array}{l}<5 \mathrm{~cm} \\
\geqslant 5 \mathrm{~cm}\end{array}$ & $\begin{array}{c}1 \text { (referent) } \\
2.86(1.14-7.21)\end{array}$ & 0.026 & $\begin{array}{c}1 \text { (referent) } \\
0.76(0.23-2.56)\end{array}$ & 0.661 \\
\hline \multicolumn{5}{|l|}{ AJCC stage } \\
\hline $\begin{array}{l}I A+I B \\
I I A+I I B \\
I I I+I V\end{array}$ & $\begin{array}{c}1 \text { (referent) } \\
3.37(0.75-15.05) \\
13.73(3.30-57.19)\end{array}$ & $\begin{array}{r}0.112 \\
<0.001\end{array}$ & \begin{tabular}{|c|}
1 (referent) \\
8.34 (0.85-82.09) \\
$49.04(6.21-387.61)$
\end{tabular} & $\begin{array}{r}0.069 \\
<0.001\end{array}$ \\
\hline \multicolumn{5}{|l|}{ CRP level } \\
\hline $\begin{array}{l}<6.9 \mathrm{mgl}^{-1} \\
\geqslant 6.9 \mathrm{mgl}^{-1}\end{array}$ & $\begin{array}{c}1 \text { (referent) } \\
3.89(2.17-6.97)\end{array}$ & $<0.001$ & $\begin{array}{c}1 \text { (referent) } \\
2.25(1.21-4.18)\end{array}$ & 0.010 \\
\hline
\end{tabular}




\begin{tabular}{|c|c|c|c|c|}
\hline & Univariate ar & alysis & Multivariate an & alysis \\
\hline Parameter & HR $(95 \% \mathrm{Cl})$ & $P$-value & HR $(95 \% \mathrm{Cl})$ & $P$-value \\
\hline \multicolumn{5}{|c|}{ Age at operation (years) } \\
\hline $\begin{array}{l}<65 \\
\geqslant 65\end{array}$ & $\begin{array}{c}1 \text { (referent) } \\
1.69(1.02-2.80)\end{array}$ & 0.043 & $\begin{array}{c}1 \text { (referent) } \\
1.48(0.87-2.50)\end{array}$ & 0.142 \\
\hline \multicolumn{5}{|l|}{ Gender } \\
\hline $\begin{array}{l}\text { Female } \\
\text { Male }\end{array}$ & $\begin{array}{c}1 \text { (referent) } \\
1.13(0.68-1.88)\end{array}$ & 0.637 & $\begin{array}{c}1 \text { (referent) } \\
1.06(0.63-1.79)\end{array}$ & 0.838 \\
\hline \multicolumn{5}{|c|}{ Tumour depth } \\
\hline $\begin{array}{l}\text { Superficial } \\
\text { Deep }\end{array}$ & $\begin{array}{c}1 \text { (referent) } \\
1.16(0.64-2.07)\end{array}$ & 0.628 & $\begin{array}{c}1 \text { (referent) } \\
0.89(0.48-1.64)\end{array}$ & 0.707 \\
\hline \multicolumn{5}{|c|}{ Tumour grade } \\
\hline $\begin{array}{l}\text { G1 } \\
\text { G2 } \\
\text { G3 }\end{array}$ & $\begin{array}{c}1 \text { (referent) } \\
3.90(1.28-11.83) \\
4.55(1.63-12.71)\end{array}$ & $\begin{array}{l}0.016 \\
0.004\end{array}$ & $\begin{array}{c}1 \text { (referent) } \\
0.34(0.03-3.38) \\
0.11(0.01-0.90)\end{array}$ & $\begin{array}{l}0.355 \\
0.039\end{array}$ \\
\hline \multicolumn{5}{|l|}{ Tumour size } \\
\hline $\begin{array}{l}<5 \mathrm{~cm} \\
\geqslant 5 \mathrm{~cm}\end{array}$ & $\begin{array}{c}1 \text { (referent) } \\
1.99(0.98-4.04)\end{array}$ & 0.057 & $\begin{array}{c}1 \text { (referent) } \\
0.71 \text { (0.26-1.92) }\end{array}$ & 0.502 \\
\hline \multicolumn{5}{|l|}{ AJCC stage } \\
\hline $\begin{array}{l}I A+I B \\
I I A+I I B \\
I I I+I V\end{array}$ & $\begin{array}{c}1 \text { (referent) } \\
3.57(1.06-12.02) \\
9.34(2.87-30.42)\end{array}$ & $\begin{array}{r}0.040 \\
<0.001\end{array}$ & $\begin{array}{c}1 \text { (referent) } \\
14.36(1.13-181.76) \\
61.73(5.76-661.00)\end{array}$ & $\begin{array}{l}0.040 \\
0.001\end{array}$ \\
\hline \multicolumn{5}{|l|}{ CRP level } \\
\hline $\begin{array}{l}<6.9 \mathrm{mgl}^{-1} \\
\geqslant 6.9 \mathrm{mgl}^{-1}\end{array}$ & $\begin{array}{c}1 \text { (referent) } \\
2.89(1.74-4.83) \\
\end{array}$ & $<0.001$ & $\begin{array}{c}1 \text { (referent) } \\
1.97(1.13-3.45)\end{array}$ & 0.017 \\
\hline
\end{tabular}

To evaluate the impact of the plasma CRP level on the predictive ability of the Kattan nomogram, calibration and calculation of the c-index were performed and compared with the prediction accuracy of the original Kattan nomogram (Figure 4). The c-index associated with the original Kattan nomogram in our cohort was 0.74. The calibration plot in Figure 5 demonstrates the extent of agreement between the predictions made by the original nomogram supplemented by CRP and the actual outcomes documented in our cohort. In this plot, values on the $\mathrm{x}$ axis represent probabilities that were calculated using the nomogram, and values on the y axis represent the observed 12-year sarcoma-specific survival for patients in our cohort. The diagonal line represents the performance of an ideal nomogram, for which predicted outcomes would correspond perfectly with actual outcomes. When we added the plasma CRP level to the Kattan nomogram, the concordance index improved to 0.77. Furthermore, a higher level of calibration could be observed when the modified nomogram was applied to our cohort (Figure 5).

\section{DISCUSSION}

In the present study, elevated pre-operative plasma CRP levels were found to be independently associated with poor clinical
Table 4. Univariate and multivariate Cox proportional analysis regarding overall survival

\begin{tabular}{|l|c|c|c|c|}
\hline \multicolumn{4}{|c|}{ Univariate analysis } & Multivariate analysis \\
\hline Parameter & HR (95\% Cl) & P-value & HR (95\% Cl) & P-value \\
\hline Age at operation (years) \\
\hline $\begin{array}{l}<65 \\
\geqslant 65\end{array}$ & $\begin{array}{c}1 \text { (referent) } \\
1.74(1.17-2.58)\end{array}$ & 0.006 & $\begin{array}{c}1 \text { (referent) } \\
1.50(1.00-2.26)\end{array}$ & 0.050 \\
\hline
\end{tabular}

Gender

\begin{tabular}{|l|c|c|c|c|}
\hline $\begin{array}{l}\text { Female } \\
\text { Male }\end{array}$ & $\begin{array}{c}1 \text { (referent) } \\
0.88(0.59-1.31)\end{array}$ & 0.530 & $\begin{array}{c}1 \text { (referent) } \\
0.72(0.48-1.09)\end{array}$ & 0.116 \\
\hline
\end{tabular}

Tumour depth

\begin{tabular}{|l|c|c|c|c|}
\hline $\begin{array}{l}\text { Superficial } \\
\text { Deep }\end{array}$ & 1 (referent) & 0.542 & 1 (referent) & 0.667 \\
\hline
\end{tabular}

Tumour grade

\begin{tabular}{|l|c|r|c|c|}
\hline G1 & 1 (referent) & 0.368 & 1 (referent) & 0.034 \\
G2 & $1.52(0.61-3.78)$ & $<0.001$ & $0.16(0.03-0.87)$ & 0.111 \\
G3 & $4.83(2.33-10.02)$ & & $0.30(0.07-1.32)$ & \\
\hline
\end{tabular}

Tumour size

\begin{tabular}{|l|c|c|c|c|}
\hline$<5 \mathrm{~cm}$ & 1 (referent) & 0.093 & 1 (referent) & 0.816 \\
$\geqslant 5 \mathrm{~cm}$ & $1.58(0.93-2.71)$ & & $0.91(0.41-2.02)$ & \\
\hline
\end{tabular}

\section{AJCC stage}

\begin{tabular}{|l|c|r|r|r|}
\hline IA + IB & 1 (referent) & 0.026 & 1 (referent) & 0.009 \\
IIA + IIB & $2.72(1.13-6.57)$ & $<0.001$ & $10.77(1.82-63.89)$ & $<0.001$ \\
III + IV & $8.45(3.64-19.59)$ & & $23.70(4.44-126.52)$ & \\
\hline
\end{tabular}

CRP level

\begin{tabular}{|c|c|c|c|c|}
\hline$<6.9 \mathrm{mgl}^{-1}$ & 1 (referent) & $<0.001$ & 1 (referent) & 0.047 \\
$\geqslant 6.9 \mathrm{mgl}^{-1}$ & $2.38(1.60-3.54)$ & & $1.54(1.01-2.35)$ & \\
\hline
\end{tabular}

Abbreviations: $\mathrm{AJCC}=$ American Joint Committee on Cancer; $\mathrm{Cl}=$ confidence interval; $\mathrm{CRP}=\mathrm{C}$-reactive protein; $\mathrm{HR}=$ hazard ratio

outcome for CSS, DFS and OS in a large cohort of STS patients. In addition, we demonstrated that integrating novel biomarkers such as the plasma CRP level to well-established prognostic tools such as the Kattan nomogram, might lead to an improved predictive ability of such prognostic risk models. There have been many efforts to investigate the relationship between CRP levels and prognosis in several types of cancer, including oesophageal, hepatocellular, colorectal, renal cell carcinoma, ovarian and advanced non-small cell lung cancer (Hashimoto et al, 2005; Gockel et al, 2006; Lamb et al, 2006; Crozier et al, 2007; Hefler et al, 2008; Gagnon et al, 2010). Data regarding the influence of CRP blood levels on clinical outcome of STS patients are sparse. In the first study, Nakanishi et al (2002) reported elevated pre-operative CRP levels in 65\% of 46 malignant fibrous histiocytoma patients. They selected a CRP cutoff value of $>10 \mathrm{mgl}^{-1}$ and identified elevated CRP levels as a poor prognostic factor in univariate analyses for metastases-free and overall survival. However, as the cohort of patients was rather small, no data of the independent prognostic relevance in multivariate analyses had been reported (Nakanishi et al, 2002). In a recent study, increased CRP levels (cutoff value of $>3 \mathrm{mgl}^{-1}$ ) in $18 \%$ of 102 STS patients were significantly associated with a high tumour grade and decreased DFS in multivariate analysis, whereas a statistical significant association for OS could only be demonstrated in univariate analysis (Nakamura et al, 2012). In another larger study, Nakamura et al (2013) reviewed 322 STS patients and described an elevated CRP level (cutoff value of $>10 \mathrm{mgl}^{-1}$ ) 


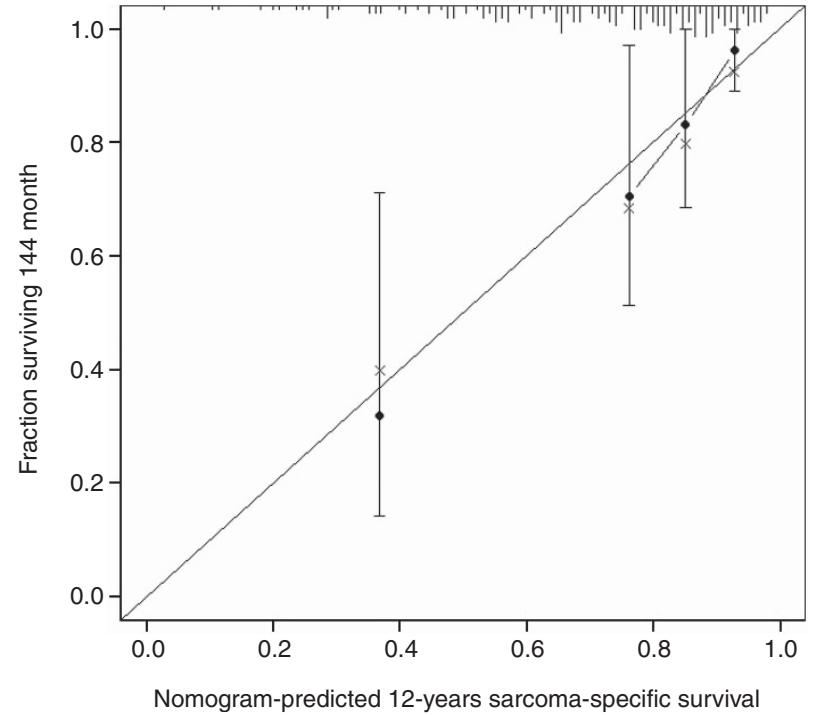

Figure 5. Calibration of the Kattan nomogram supplemented by C-reactive protein. Horizontal axis is one minus the nomogram's predicted probability of 12 years sarcoma-specific death. Vertical axis is the actual sarcoma-specific survival estimated at 12 years using the Kaplan-Meier method. Diagonal line indicates the reference line on which an ideal nomogram would lie. Solid black line indicates performance of the present nomogram. • subcohorts of database; $\times$, bootstrap-corrected estimate of nomogram's performance with 200 resamples. Error bars indicate $95 \%$ confidence interval.

before initial surgical treatment as an independent poor prognostic factor for disease-specific survival and local recurrence-free rate in patients with high-grade sarcomas. As the authors state correctly, further large-scale validation studies in independent cohorts are necessary to confirm their findings (Nakamura et al, 2013). In our study, which is in line with the finding from Nakamura et al (2013), we could also confirm an independent prognostic role for elevated CRP levels and decreased cancer- and disease-free survival. Furthermore, supplementing the Kattan nomogram by the plasma CRP level improved the predictive ability of the c-index by $3 \%$. An explanation for this association remains speculative, but several previously observational and experimental studies add information to this hypothesis. CRP is synthesised mainly by hepatocytes, and its production is induced by interleukin-6 (IL-6) and IL-1 (Zhang et al, 1995; Weinhold and Rüther, 1997). Under physiological condition, CRP is present in human blood in rather low levels, but in response to cytokines induced by inflammation or trauma the concentration increases even 1000-fold (Macintyre et al, 1982). After the removal of inflammatory stimulus, the blood levels of CRP decreases rapidly (Claus et al, 1977). CRP acts not only as a biomarker for inflammation but also represents a modulator of the immunological system, acts like a cytokine and has an important role in host defense and inflammation with various effects on cells and biological processes (Volanakis, 2001). Elevated blood levels of this protein were also observed in cardiovascular disease, diabetes and cancer (Ridker et al, 2000; Rota et al, 2005; Heikkilä et al, 2007).

The molecular basis of the relationship between elevated plasma CRP levels and poor clinical outcome in cancer patients has not been fully elucidated, and several possible explanations have been postulated. First, tumour growth can induce tissue inflammation and hence increase the CRP levels (Coussens and Werb, 2002). Second, CRP could represent an indicator of an immune response of the host to tumour antigens (Ramsey et al, 2006). Third, cancer cells and inflammatory cells of the tumour microenvironment, such as granulocytes, lymphocytes and macrophages, could increase the production of inflammatory cytokines, which may induce CRP production in cancer patients (Coussens and Werb, 2002; Wigmore et al, 2002; Nozoe et al, 2003). Rutkowski et al (2002) observed that increased plasma levels of IL-6 were found in approximately $60 \%$ of STS patients and that the levels correlated with tumour grade and size.

There are a few limitations of the present study. It is limited by its retrospective nature, and unknown sources of bias may exist in the findings. What is more, the heterogeneous group of patients is another limitation. However, as STSs are rare tumours, pooling of different histological subtypes by tumour grade is well established in prognostic and therapeutic studies.

In conclusion, our single-centre experience clearly confirms the potential prognostic utility of pre-operative plasma CRP levels as an independent prognostic marker in STS patients who underwent curative surgical resection. These results indicate that patients with high pre-operative CRP levels might be considered as candidates for additional, more aggressive treatment approaches or more stringent follow-up schedules. However, further large-scale prospective multicentre studies are now warranted to confirm and extend these findings.

\section{ACKNOWLEDGEMENTS}

We thank Slave Trajanoski from the Center for Medical Research, Medical University of Graz for his assistance.

\section{CONFLICT OF INTEREST}

The authors declare no conflict of interest.

\section{REFERENCES}

Absenger G, Szkandera J, Pichler M, Stotz M, Arminger F, Weissmueller M, Schaberl-Moser R, Samonigg H, Stojakovic T, Gerger A (2013) A derived neutrophil to lymphocyte ratio predicts clinical outcome in stage II and III colon cancer patients. Br J Cancer 109(2): 395-400.

Balkwill F, Mantovani A (2001) Inflammation and cancer: back to Virchow? Lancet 357: 539-545.

Claus DR, Siegel J, Petras K, Osmand AP, Gewurz H (1977) Interactions of C-reactive protein with the first component of human complement. J Immunol 119: 187-192.

Coindre JM (2006) Grading of soft tissue sarcomas: review and update. Arch Pathol Lab Med 130: 1448-1453.

Cormier JN, Pollock RE (2004) Soft tissue sarcomas. CA Cancer J Clin 54: 94-109.

Coussens LM, Werb Z (2002) Inflammation and cancer. Nature 420: 860-867. Crozier JE, McKee RF, McArdle CS, Angerson WJ, Anderson JH, Horgan PG, McMillan DC (2007) Preoperative but not postoperative systemic inflammatory response correlates with survival in colorectal cancer. Br J Surg 94: 1028-1032.

Edge SB, Byrd DR, Compton CC, Fritz AG, Greene FL, Trotti A (2010) Soft tissue sarcoma. In: AJCC Cancer Staging Manual. 7th edn pp 291-296. Springer: New York, NY, USA.

Fletcher CDM, Bridge JA, Hogendoorn P, Mertens F (2013) WHO Classification of Tumours of Soft Tissue and Bone. In WHO Classification of Tumours. 4th edn, Vol. 5IARC Press: Lyon, France.

Gagnon B, Abrahamowicz M, Xiao Y, Beauchamp ME, MacDonald N, Kasymjanova G, Kreisman H, Small D (2010) Flexible modeling improves assessment of prognostic value of $\mathrm{C}$-reactive protein in advanced nonsmall cell lung cancer. Br J Cancer 102: 1113-1122.

Gockel I, Dirksen K, Messow CM, Junginger T (2006) Significance of preoperative C-reactive protein as a parameter of the perioperative course and long-term prognosis in squamous cell carcinoma and adenocarcinoma of the oesophagus. World J Gastroenterol 12: 3746-3750.

Groblewska M, Mroczko B, Wereszczyńska-Siemiatkowska U, Kedra B, Lukaszewicz M, Baniukiewicz A, Szmitkowski M (2008) Serum 
interleukin 6 (IL-6) and C-reactive protein (CRP) levels in colorectal adenoma and cancer patients. Clin Chem Lab Med 46: 1423-1428.

Hara M, Matsuzaki Y, Shimuzu T, Tomita M, Ayabe T, Enomoto Y, Onitsuka T (2007) Preoperative serum C-reactive protein level in non-small cell lung cancer. Anticancer Res 27: 3001-3004.

Hashimoto K, Ikeda Y, Korenaga D, Tanoue K, Hamatake M, Kawasaki K, Yamaoka T, Iwatani Y, Akazawa K, Takenaka K (2005) The impact of preoperative serum $\mathrm{C}$-reactive protein on the prognosis of patients with hepatocellular carcinoma. Cancer 103: 1856-1864.

Hefler LA, Concin N, Hofstetter G, Marth C, Mustea A, Sehouli J, Zeillinger R, Leipold H, Lass H, Grimm C, Tempfer CB, Reinthaller A (2008) Serum $\mathrm{C}$-reactive protein as independent prognostic variable in patients with ovarian cancer. Clin Cancer Res 14: 710-714.

Heikkilä K, Ebrahim S, Lawlor DA (2007) A systematic review of the association between circulating concentrations of $\mathrm{C}$ reactive protein and cancer. J Epidemiol Community Health 61: 824-833.

Kattan MW, Leung DH, Brennan MF (2002) Postoperative nomogram for 12-year sarcoma-specific death. J Clin Oncol 20: 791-796.

Lamb GW, McMillan DC, Ramsey S, Aitchison M (2006) The relationship between the preoperative systemic inflammatory response and cancerspecific survival in patients undergoing potentially curative resection for renal clear cell cancer. Br J Cancer 94: 781-784.

Liegl-Atzwanger B, Hofmann G, Leithner A, Beham A (2009) Undifferentiated high-grade pleomorphic sarcoma (UHPS): Diagnostic criteria, differential diagnosis, and treatment. An attempt to erasure the misnomer MFH. Eur Surg 41: 143-149.

Macintyre SS, Schultz D, Kushner I (1982) Biosynthesis of C-reactive protein. Ann NY Acad Sci 389: 76-87.

Nakamura T, Grimer R, Gaston C, Francis M, Charman J, Graunt P, Uchida A, Sudo A, Jeys L (2013) The value of C-reactive protein and comorbidity in predicting survival of patients with high grade soft tissue sarcoma. Eur J Cancer 49: 377-385.

Nakamura T, Matsumine A, Matsubara T, Asanuma K, Uchida A, Sudo A (2012) Clinical significance of pretreatment serum C-reactive protein level in soft tissue sarcoma. Cancer 118: 1055-1061.

Nakanishi H, Araki N, Kudawara I, Kuratsu S, Matsumine A, Mano M, Naka N, Myoui A, Ueda T, Yoshikawa H (2002) Clinical implications of serum C-reactive protein levels in malignant fibrous histiocytoma. Int J Cancer 99: 167-170.

Nozoe T, Korenaga D, Futatsugi M, Saeki H, Maehara Y, Sugimachi K (2003) Immunohistochemical expression of C-reactive protein in squamous cell carcinoma of the esophagus-significance as a tumor marker. Cancer Lett 192: 89-95.
Pichler M, Hutterer GC, Stoeckigt C, Chromecki TF, Stojakovic T, Golbeck S, Eberhard K, Gerger A, Mannweiler S, Pummer K, Zigeuner R (2013) Validation of the pre-treatment neutrophil-lymphocyte ratio as a prognostic factor in a large European cohort of renal cell carcinoma patients. Br J Cancer 108: 901-907.

Ramsey S, Lamb GW, Aitchison M, McMillan DC (2006) The longitudinal relationship between circulating concentrations of C-reactive protein, interleukin-6 and interleukin-10 in patients undergoing resection for renal cancer. Br J Cancer 95: 1076-1080.

Ridker PM, Hennekens CH, Buring JE, Rifai N (2000) C-reactive protein and other markers of inflammation in the prediction of cardiovascular disease in women. $N$ Engl J Med 342: 836-843.

Rota S, Yildirim B, Kaleli B, Aybek H, Duman K, Kaptanoğlu B (2005) $\mathrm{C}$-reactive protein levels in non-obese pregnant women with gestational diabetes. Tohoku J Exp Med 206: 341-345.

Rutkowski P, Kaminska J, Kowalska M, Ruka W, Steffen J (2002) Cytokine serum levels in soft tissue sarcoma patients: correlations with clinicopathological features and prognosis. Int J Cancer 100: 463-471.

Stefanovski PD, Bidoli E, De Paoli A, Buonadonna A, Boz G, Libra M, Morassut S, Rossi C, Carbone A, Frustaci S (2002) Prognostic factors in soft tissue sarcomas: a study of 395 patients. Eur J Surg Oncol 28: 153-164.

Stojadinovic A, Leung DH, Hoos A, Jaques DP, Lewis JJ, Brennan MF (2002) Analysis of the prognostic significance of microscopic margins in 2084 localized primary adult soft tissue sarcomas. Ann Surg 235: 424-434.

Volanakis JE (2001) Human C-reactive protein: expression, structure, and function. Mol Immunol 38: 189-197.

Weinhold B, Rüther U (1997) Interleukin-6-dependent and -independent regulation of the human C-reactive protein gene. Biochem J 327: $425-429$.

Wigmore SJ, Fearon KC, Sangster K, Maingay JP, Garden OJ, Ross JA (2002) Cytokine regulation of constitutive production of interleukin- 8 and -6 by human pancreatic cancer cell lines and serum cytokine concentrations in patients with pancreatic cancer. Int J Oncol 21: 881-886.

Zhang D, Jiang SL, Rzewnicki D, Samols D, Kushner I (1995) The effect of interleukin-1 on C-reactive protein expression in Hep3B cells is exerted at the transcriptional level. Biochem J 310: 143-148.

This work is published under the standard license to publish agreement. After 12 months the work will become freely available and the license terms will switch to a Creative Commons AttributionNonCommercial-Share Alike 3.0 Unported License. 